\title{
Nuclear Fuel Cycle Front End Chemistry
}

\author{
Patrick Blanpain*, Georges Capus ${ }^{\mathrm{a}}$, and Jean-Claude Palussière ${ }^{\mathrm{b}}$
}

\begin{abstract}
A broad description of the main chemical processes involved at each main step of the nuclear fuel cycle, from uranium mining to nuclear grade uranium oxide preparation for nuclear fuel fabrication is provided.
\end{abstract}

Keywords: Conversion · Enrichment · Mining · Nuclear fuel · Uranium

\section{Introduction}

In contrast to other energy production sources, which involve basically burning raw materials as they are extracted (coal, natural gas) or after chemical modification (oil and gas from crude oil or tar sands...) the fuel for nuclear power plants is a very complex object. In brief, it can be described as a heat-exchanger designed to combine high thermo-hydraulics performance and fission product confinement, containing the nuclear material in the form of ceramic oxide pellets.

The industrial steps leading to its fabrication are usually named the front-end of the nuclear fuel cycle (the back-end deals with 'spent' fuel elements removed from the reactor core after usage for further processing).
The typical nuclear fuel cycle front end for light water reactors like EPR (European Pressurised Reactor) is composed of four major steps:

- Uranium mining: i.e. the recovery of uranium concentrates as raw material.

- Uranium conversion: i.e. the chemical purification of concentrates and their transformation into $\mathrm{UF}_{6}$.

- Uranium enrichment: i.e. its isotopic modification to a higher fissile uranium content (enriched uranium).

- Fuel fabrication: i.e. the production of enriched $\mathrm{UO}_{2}$ powder, its physical transformation into pellets, and finally its incorporation into a metallic structure, the fuel assembly.

Only the isotopic enrichment step does not involve chemical processes under current industrial practices.

AREVA, the EPR provider, is also involved at each step of the fuel cycle. Regarding the front-end of this fuel cycle, the AREVA's share of uranium concentrate production was about $15 \%$ of the world total, for $\mathrm{UF}_{6}$ production $28 \%$ of the world total, and for enrichment about $25 \%$ of the world total.

\section{Uranium Mining}

\subsection{Uranium Deposits: The Source of Nuclear Fuel}

Today the element uranium has a unique use: fuelling nuclear reactors, mainly for power production and marginally nuclear research applications or naval propulsion.

Uranium is present in the earth's crust at an average concentration of about $2.7 \mathrm{ppm}$. It is currently recovered from uranium-rich rocks (ores) showing concentrations ranging from about $200 \mathrm{ppm}$ (low-grade ores of South Africa where uranium is recovered as a gold by-product) up to $20 \%$ on average (very high-grade uranium ores of the Saskatchewan Province in Canada).

Within a concentration of uranium (a resource), 'ore-bodies' boundaries are defined by a grade limit named cut-off grade resulting from an economic definition of what is worth putting into the mining and milling process under the given market conditions.

Typical uranium ore-bodies range in size from a few hundred tons of uranium to a few hundred thousand tons. The largest known ore-body contains a total resource of about 1.3 million tons of uranium associated with copper (the Olympic Dam deposit in Australia).

With the noticeable exceptions of South Africa 'Witwatersrand-type' deposits where uranium has been concentrated mainly by a physical mechanism (density sorting), and for phosphate rocks where uranium was mainly trapped by ion substitution in the lattice of the phosphate mineral (apatite), all the uranium concentrations result from chemical cycles of dissolution in source rocks by oxidising waters, transportation in surface and groundwater as uranium complex (mainly uranyl-carbonates), and precipitation at the contact with reducing compounds (sulphides and/or organic material).

The most widespread minerals in the ores are oxides such as uraninite and pitchblende (basically a composition varying from $\mathrm{UO}_{2}$ to $\mathrm{UO}_{2,25}$ according to formation conditions and partial oxidation following the radioactive decay of uranium), silicates such as coffinite $\left(\mathrm{U}\left(\mathrm{SiO}_{4}\right)_{1-\mathrm{x}} \mathrm{OH}_{4 \mathrm{x}}\right)$ and titanate such as brannerite ((U, Ca, F, Th, $\left.\mathrm{Y})(\mathrm{Ti}, \mathrm{Fe})_{2} \mathrm{O}_{6}\right)$.

Uranium is commonly associated with other minor or trace elements which are part of uranium-bearing minerals $(\mathrm{V}, \mathrm{Cu} . .$. or associated as separate minerals (As, Se, Mo, Co, Ni...). Several of these elements 
are unsuitable in commercial concentrates and must be removed during the recovery process.

\subsection{Conventional Mining and Milling}

With conventional mining and milling operations, the first step is to extract the ore from the ground by mining methods. Depending upon the depth and the shape of the ore-body, the ore can be mined-out from open-pits or from underground mines.

The second step is to crush and grind the mined ore fragments ('comminution') to a size optimum for uranium leaching with acidic or carbonate adjusted solutions. The third step is to separate the milled ore ('mill tailings') and the uranium bearing solution. The fourth step is to purify the solutions, precipitate uranium concentrates and subsequently to dry and/or calcinate a final product which is drummed, ready for shipment.

The leaching stage can be achieved in a dynamic circuit, usually in agitated tanks pachucas or autoclaves or by percolating leaching solutions through a pile of crushed rocks ('heap leaching').

Because in most uranium-bearing minerals part of the uranium is in reduced form (tetravalent uranium), the first step is to oxidise it to the very soluble hexavalent form. Oxidation of the uranium is usually achieved by use of a chemical oxidant such as hydrogen peroxide ferric ion, or sodium chlorate or by use of pure oxygen.

The leaching solution composition is determined by the composition of the ore. The most important parameter is the carbonate content of the ore. In the case of low carbonate content, the leach solution is usually a sulphuric acid solution. In the case of high carbonate content, the leaching solution is an alkaline-carbonate solution (usually $\mathrm{Na}_{2} \mathrm{CO}_{3}$ ).

\section{- The Classic Acid Leaching Route}

Oxidation of $\mathrm{UO}_{2}$ using ferric ions

$\mathrm{UO}_{2}+2 \mathrm{Fe}^{3+} \rightarrow \mathrm{UO}_{2}{ }^{2+}+2 \mathrm{Fe}^{2+}$

Dissolution as uranyl sulphates

$\mathrm{UO}_{2}^{2+}+\mathrm{SO}_{4}^{2-} \rightarrow \mathrm{UO}_{2} \mathrm{SO}_{4}$

$\mathrm{UO}_{2} \mathrm{SO}_{4}+\mathrm{SO}_{4}{ }^{2-} \rightarrow\left[\mathrm{UO}_{2}\left(\mathrm{SO}_{4}\right)_{2}\right]^{2-}$

$\left[\mathrm{UO}_{2}\left(\mathrm{SO}_{4}\right)_{2}\right]^{2-}+\mathrm{SO}_{4}{ }^{2-} \rightarrow\left[\mathrm{UO}_{2}\left(\mathrm{SO}_{4}\right)_{3}\right]^{4-}$

- The Classic Alkaline Leaching Route

Oxidation of $\mathrm{UO}_{2}$ using oxygen

$2 \mathrm{UO}_{2}+\mathrm{O}_{2} \rightarrow 2 \mathrm{UO}_{3}$

Dissolution by bicarbonate ion as uranylcarbonate
$\mathrm{UO}_{3}+\mathrm{CO}_{3}^{2-}+2 \mathrm{HCO}^{3-} \rightarrow$
$\left[\mathrm{UO}_{2}\left(\mathrm{CO}_{3}\right)_{3}\right]^{4-}+\mathrm{H}_{2} \mathrm{O}$

Bicarbonate prevents premature precipitation of sodium diuranate $\left(\mathrm{Na}_{2} \mathrm{U}_{2} \mathrm{O}_{7}\right)$ in the presence of hydroxyl ions.

After a sufficient leach time, the solutions and the solid residues are separated through a liquid-solid separation (typically thickeners, filters, cyclones, other types of classifiers). The 'mill tailings' are washed and neutralised, then disposed of at dedicated and monitored sites.

Following the liquid-solid separation, uranium-bearing solutions are usually concentrated and uranium is extracted by organic solvent extraction (SX) through a contact-stage and liquid-liquid separation or by ion-exchange (IX) on resins. Usually the solvent is a long chain aliphatic amine diluted in kerosene. Resins are frequently chemically activated polymers of poly-styrene-di-vinyl benzene.

After the extraction stage, the uranium loaded on the organic phase is 'stripped' or 'eluted' by an aqueous solution of ammonium sulphate, sodium chloride, sulphuric acid or nitric acid.

The aqueous solution now containing the uranium or 'pregnant solution' then enters the uranium precipitation stage. Precipitation is achieved by using either a base (ammonia, lime, magnesia or caustic soda) or hydrogen peroxide. In the first case the precipitate is a mixture of uranates and other compounds, in the second case, the precipitate is a peroxide of uranium $\left(\mathrm{UO}_{4}, \mathrm{xH}_{2} \mathrm{O}\right)$. The precipitates are recovered through filtration, then dried and/or calcined. Depending upon the chosen precipitation reagent, commercial concentrates consist of various chemical forms and uranium grades. The retained form to express the uranium commercial content is usually the tri-uranium octoxide $\mathrm{U}_{3} \mathrm{O}_{8}$

\subsection{In Situ Solution Mining}

In some cases, uranium ore is contained within pervious sandstone layers saturated with groundwater. These layers of sandstone will generally have a low permeability sub-layer that isolates the uranium-bearing strata. In these cases, sometimes, the ore forming process is still ongoing, but most generally fossilised. The concept of solution mining is to take advantage of the permeability of the ore by circulating leaching solutions directly in the ore-body through a pattern of injection and extraction wells. Depending upon the carbonate content, one of the two above mentioned leach routes can be retained: acid leaching or alkaline leaching. The remaining part of the process is then rather similar to the conventional method.

Except when the ground water is of poor quality not suitable for water supply (salted water...) the aquifer is generally reclaimed to satisfactory parameters, using washing solutions and reverse osmosis to remove all mobilised pollutants.

This 'unconventional' mining method represented about $17 \%$ of world production in 2004.

\subsection{Uranium Recovery as a By-product}

It is not the purpose of this paper to fully cover this topic, but it is of interest to know that uranium is also currently recovered from copper production in Australia and from gold production in South Africa (about $10 \%$ and $2 \%$ of world production respectively). In the recent past, uranium was also recovered from phosphoric acid production from phosphate rocks extracted mainly in Florida and Morocco.

\section{Uranium Concentrate Refining (From Raw Material to Nuclear Purity Grade Uranium)}

All the uranium concentrates produced at mine sites (about 40,000 tU in 2004) are sent to one of the few conversion plants (only six large commercial scale plants worldwide). At these plants they enter the following route:

- Concentrate Sampling and Acceptance Procedure: first goal: weigh and classify, with the required accuracy the uranium content of the concentrate batches, mainly for safeguards and commercial purposes; second goal: verify the quality of the uranium concentrates and their compliance with acceptance limits (in order to meet ASTM specifications downstream).

- Concentrate Preparation Before Entering the Conversion Process:

- Dry process: the concentrates enter a calciner for removal of volatile compounds such as water, carbonates and organic material. The calcinate is agglomerated using a spray of a convenient aqueous solution. The particles are dried in a rotary dryer $\left(370-480{ }^{\circ} \mathrm{C}\right)$ then crushed and screened to enter the reduction stage, or

- Wet process: this starts with a digestion of the concentrates in nitric acid, gelatinous insoluble silica is often removed from the uranyl nitrate hexahydrate solutions by a filtration on a precoated rotary drum vacuum filter (Comurhex and BNFL) after an optimised residence time in the dissolver circuit.

- Purification Through Solvent Extraction (Wet Process): process using tributyl phosphate (TBP) is the only one currently in use. Other solvents were 
tested, mainly in the 1950s, but none of them were retained for industrial scale refining operations (even if some are in use at uranium mills or for special uranium recovery as a by-product).

- Concentration of the uranyl nitrate solution through evaporation to thermal decomposition of uranyl hexahydrate, or precipitation with gaseous ammonia into ammonium diuranate (ADU).

- Calcination: yields to uranium trioxide $\left(\mathrm{UO}_{3}\right)$ at $500{ }^{\circ} \mathrm{C}$.

\section{Uranium Conversion to $\mathrm{UF}_{6}$}

\subsection{Why Convert Uranium to $\mathrm{UF}_{6}$ ?}

$\mathrm{UF}_{6}$ is the suitable form to enter the isotopic enrichment stage with the two current industrial processes; gaseous diffusion and gas centrifugation. This chemical form was retained for its physical properties. At room temperature it is a white volatile solid. At $64{ }^{\circ} \mathrm{C}$ it melts at low pressure to a colourless very dense liquid. Its triple point low temperature (around $65^{\circ} \mathrm{C}$ ) allows it to be easily sublimed to a gaseous form by heating. It is also easily desublimised, back to a solid form in cold traps and cylinders.

Another advantage is that natural fluorine consists of only one isotope. This property avoids complicating the separation process by having a larger number of compounds of different molecular mass.

\subsection{The Conversion Process}

The conversion process covers the purification stage in Western countries, whereas in the former Eastern block conversion was only started at the fluorination stage, with the ability to directly fluorinate $\mathrm{U}_{3} \mathrm{O}_{8}$.

After purification, we have:

- Reduction of uranium into dioxide $\left(\mathrm{UO}_{2}\right)$ using hydrogen or ammonia

- Hydrofluorination: reaction with hydrogen fluoride (HF) to make uranium tetrafluoride $\mathrm{UF}_{4}$ (or 'green salt')

Production of Fluorine $\left(F_{2}\right)$ : fluorine production for uranium fluorination is done without exception by anhydrous hydrogen fluoride electrolysis. The $\mathrm{F}_{2}$ gas, a very strong oxidant, is a hazardous chemical, toxic and a highly corrosive material which reacts in a violent manner with a number of compounds such as hydrogen, water, organic materials. As it is very difficult to transport it on a large scale, $\mathrm{F}_{2}$ is produced on line for uranium conversion, by far the main industrial use (approximately 50\% of the consumption). It is worth mentioning that for the above-mentioned reasons, these sources of gaseous fluorine are also used to produce other fluorine products besides $\mathrm{UF}_{6}$.

- Fluorination of $U F_{4}$ by reaction of gas- eous fluorine for uranium hexafluoride $\left(\mathrm{UF}_{6}\right)$ production; two processes are used for this stage:

- High-temperature fluorination by burning pulverised $\mathrm{UF}_{4}$ in gaseous $\mathrm{F}_{2}$ in flame reactors (flame temperature $1400{ }^{\circ} \mathrm{C}$ ). This process is widely used at Comurhex, Cameco, and Rosatom plants and as such represents the major share of installed capacities, or

- Medium-temperature fluorination by reaction of gaseous $F_{2}$ on pulverised $\mathrm{UF}_{4}$ in fluidised bed reactors (fluorinators). An inert load ( $\mathrm{MgF}_{2}$ or $\mathrm{CaF}_{2}$ ) maintained at a temperature above $482{ }^{\circ} \mathrm{C}$ is fluidised by the $\mathrm{F}_{2}$ flow. This process is in use at the Honeywell (Metropolis, Illinois, USA) and BNFL (Springfields, UK) plants.

The aim of the fluorination stage is to enable the following reaction:

$$
\mathrm{UF}_{4}+\mathrm{F}_{2} \rightarrow \mathrm{UF}_{6}
$$

with also the fluorination of $\mathrm{UO}_{2}$ and $\mathrm{UO}_{2} \mathrm{~F}_{2}$, two major impurities contained in $\mathrm{UF}_{4}$ at levels between 1 to $2 \%$ each of the total feed, according to the following reactions:

$$
\begin{aligned}
& \mathrm{UO}_{2}+3 \mathrm{~F}_{2} \rightarrow \mathrm{UF}_{6}+\mathrm{O}_{2} \\
& \mathrm{UO}_{2} \mathrm{~F}_{2}+2 \mathrm{~F}_{2} \rightarrow \mathrm{UF}_{6}+\mathrm{O}_{2}
\end{aligned}
$$

- Uranium Hexafluoride Purification by Distillation: in the case of the dry process, a fractionated distillation is used for crude $\mathrm{UF}_{6}$ purification.

The hexafluoride $\left(\mathrm{UF}_{6}\right)$ produced in the flame reactor as a gas is then crystallised in cold traps before being conditioned in special containers for transportation to enrichment plants.

$\mathrm{UF}_{6}$ reacts with water, and consequently with moisture contained in air, by creating toxic compounds: hydrofluoric acid and uranyl fluoride

$$
\mathrm{UF}_{6}+2 \mathrm{H}_{2} \mathrm{O} \rightarrow 4 \mathrm{HF}+\mathrm{UO}_{2} \mathrm{~F}_{2}
$$

\subsection{The Uranium Isotopic Enrichment Process}

Natural uranium mainly consists of $238 \mathrm{U}$ (99.69 weight \%) and to a lesser extent $235 \mathrm{U}$ (0.711 weight \%), plus trace amounts of $234 \mathrm{U}$, a decay product of $238 \mathrm{U}$. The current world fleet of nuclear power plants is basically based upon the fission of $235 \mathrm{U}$. These reactors usually require a $235 \mathrm{U}$ content significantly higher than in natural uranium, in the range of $3-5 \% 235 \mathrm{U}$. Therefore an isotopic enrichment is necessary.

Two enrichment processes are presently deployed in large-scale commercial operations: gaseous diffusion and gas centrifugation. These two processes are based on the mass difference of the two atoms and in practice on the fact that a $235 \mathrm{UF}_{6}$ molecule is slightly lighter than a $238 \mathrm{UF}_{6}$ molecule and behaves accordingly in a gaseous mixture under given pressure and temperature conditions.

In the gaseous diffusion process, $\mathrm{UF}_{6}$ passes through a very thin porous membrane, also called a 'barrier', with billions of tiny pores per square centimetre. The lighter 235U molecule moves more quickly and therefore contacts - and passes through - the barrier more often than the heavier molecule. As a result, the gas on the other side of the barrier is slightly enriched in $235 \mathrm{U}$. Thousands of barriers are interconnected in a diffuser, at the exit of which a compressor and a cooler unit allow the enriched product to be extracted. This process has the disadvantage of consuming a huge amount of power to push the gas through the barriers. In the gas centrifugation process, $\mathrm{UF}_{6}$ is fed into a fast-spinning centrifuge and forced against the wall by centrifugal force. The heavier $238 \mathrm{U}$ molecule concentrates closer to the wall than the lighter $235 \mathrm{U}$ isotope. Lower and higher temperatures applied at the top and at the bottom of the centrifuge rotor generate a counter-current inside the centrifuge. Enriched and depleted $\mathrm{UF}_{6}$ are extracted by scoops at each end of the rotor.

In both diffusion and centrifugation processes, the enrichment operation must be repeated thousands of times to obtain the desired enrichment level. The enrichment cascade is therefore constituted by the interconnection of a very large number of elementary enrichment stages.

AREVA currently operates the Georges Besse I Plant in France located in the Rhône valley, with a capacity of about $22 \%$ of the total world capacity. This plant will be replaced by a modern centrifuge-based plant planned to start production in 2008 at the same location (project Georges Besse II). Other processes have been explored, including some based upon chemical reactions, but for the time being, the gas centrifugation process is likely to become the sole method in use by the end of next decade.

\section{5. $\mathrm{UF}_{6}$ Conversion to $\mathrm{UO}_{2}-$ Fuel Pellet Manufacturing}

In Framatome-ANP plants, fuel pellets are manufactured in two main steps: production of $\mathrm{UO}_{2}$ powder from enriched $\mathrm{UF}_{6}$ by a dry conversion process followed by pellet manufacturing by means of selected powder metallurgy processes.

\subsection{Dry Conversion Process}

A $\mathrm{UF}_{6} \rightarrow \mathrm{UO}_{2}$ dry conversion process is used by Framatome-ANP in its fuel manufacturing plants of ANF Lingen (GR), 
FANP.Inc Richland (USA) and FBFC Romans (FR). FANP operates two processes based on similar chemical reactions.

Both dry conversion processes are based on a direct hydrolysis reaction between vaporised $\mathrm{UF}_{6}$ and superheated steam, followed by a pyro-hydrolysis and a reduction in $\mathrm{H}_{2}$ atmosphere.

$$
\mathrm{UF}_{6}+2 \mathrm{H}_{2} \mathrm{O}+\mathrm{H}_{2} \rightarrow \mathrm{UO}_{2}+6 \mathrm{HF}
$$

A $\mathrm{UF}_{6}$ cylinder is heated in an autoclave in order to vaporise and to feed it at a constant flow rate to the conversion process.

Hydrolysis occurs in a static reactor in which $\mathrm{UF}_{6}$ and steam are fed simultaneously through a tubular injector. Hydrolysis is an exothermic reaction performed in the range $300-400{ }^{\circ} \mathrm{C}\left(450-500{ }^{\circ} \mathrm{C}\right.$ for $\mathrm{ANF}$ and FANP Inc.)

In the first process, $\mathrm{UO}_{2} \mathrm{~F}_{2}$ powder particles formed in the reactive flux fall to the bottom of the reactor and are conveyed into a rotating kiln where $\mathrm{UO}_{2} \mathrm{~F}_{2}$ powder is reduced to $\mathrm{UO}_{2}$ in a steam and hydrogen atmosphere.

In the second process, $\mathrm{UO}_{2} \mathrm{~F}_{2}$ powder particles formed in the reactive flux fall into a fluidised bed in a steam, nitrogen and hydrogen atmosphere; most of the fluorine is removed before the powder is fed into a rotating kiln for final defluorination and reduction to $\mathrm{UO}_{2}$.

Final defluorination reactions are quite complex: the global thermal balance is slightly negative and the process operates in the range $600-800{ }^{\circ} \mathrm{C}$. Also, the temperature profiles affect powder characteristics.

Gases from chemical reactions (HF, excess steam, nitrogen and hydrogen) are filtered through a bank of metallic sintered filters. HF and excess steam are condensed and enable pure $\mathrm{HF}$ acid to be obtained, approximately $50 \%$ concentrated. Non condensed off-gases pass through a scrubbing column before release into the atmosphere.

For $\mathrm{UO}_{2}$ powder production, the dry conversion process has become today the world's leading technology due to its main characteristics: no liquid wastes, only easily disposable acid by-product, good and stable powder characteristics in a continuous production, high safety and productivity through fully automated process monitoring and surveillance.

Hot defluorinated $\mathrm{UO}_{2}$ powder is transferred into hoppers and cools under a nitrogen blanket to prevent re-oxidation to the $\mathrm{U}_{3} \mathrm{O}_{8}$ equilibrium compound. Cooled powder is transferred to pellet manufacturing, starting with the preparatory steps of blending with various additives for specific pellet characteristics, precompaction, etc.

$\mathrm{UO}_{2}$ powder from the dry conversion process is generally highly reactive, it shows very good sintering properties; very low fluorine content is also appreciated by pellet manufacturers. To summarise: the dry conversion process produces a powder of very stable quality with a high productivity and good yield.

\subsection{Pellet Manufacturing}

Due to a rather low specific area and bulk density, the powder however does not have sufficient free flowability for direct pellet pressing, so a precompaction-granulation operation is mandatory prior to pellet pressing.

$\mathrm{UO}_{2}$ powder is blended with additives and dry lubricant to reduce wear on presses and improve pressing capabilities and with pore-former for adjustment of the pellet's final density, together with $\mathrm{U}_{3} \mathrm{O}_{8}$ from the dry recycling process of scrapped pellets and grinder sludge. Other additives may be considered to achieve specific pellet characteristics such as improved fuel fission gas release and pellet-cladding interaction (PCI) behaviour.

Blended powder is compacted in a rotating press and slugs are granulated in an oscillating granulator. Granules are returned to rotating presses that produce green pellets; these are loaded into molybdenum boats for sintering in high-temperature furnaces under hydrogen atmosphere. Sintering temperatures are in the range $1700-1800{ }^{\circ} \mathrm{C}$. The final density of pellets after sintering is specified by the fuel designer, it is higher than $95 \%$ of the theoretical density.

Sintered pellets are ground in a centreless grinder for adjustment of the outer diameter according to precise cylindrical specifications of the design. Final dimensions and visual surface conditions are inspected at $100 \%$ before the pellets are released by QC. Pellets rejected during visual inspection and grinder sludge are oxidised in a kiln to produce $\mathrm{U}_{3} \mathrm{O}_{8}$ which is directly recycled at the blending operation. Pellets complying with all specified criteria proceed to the fuel rod manufacturing shop. This process produces pellets with high density and good thermal stability (densification during resintering test) as required for good fuel in pile behaviour.

\section{Depleted Uranium Defluorination}

The isotopic enrichment operation generates a flow of uranium hexafluoride isotopically depleted in $235 \mathrm{U}$. This material represents typically $80 \%$ to $90 \%$ of the total uranium fed to the enrichment process. While these tails represent a potential source of fissile material for the future (residual 235U content and 'fertile' U238 content for fast neutron reactors), it is better to transform them into a more stable form than $\mathrm{UF}_{6}$ for long term storage.

Defluorination of this material to an oxide form $\left(\mathrm{U}_{3} \mathrm{O}_{8}\right)$ is performed at dedicated plants, so far only in France (W-plant at the Tricastin site started in 1984 with a yearly capacity of 14,000 $\mathrm{tU}$ and subsequent aqueous HF [70\% HF] recovery of about 10,000 t), but others are projected in Russia, in the US and possibly in EU.

While close to the goal of enriched $\mathrm{UF}_{6}$ transformation to oxides pursued by fuel fabricators (see above), depleted $\mathrm{UF}_{6}$ defluorination must deal with far larger quantities and annual flows (by an order of magnitude).

Process:

- Hydrolysis of $\mathrm{UF}_{6}$ at $300{ }^{\circ} \mathrm{C}$ in a static reactor to $\mathrm{UO}_{2} \mathrm{~F}_{2}$ (uranyl fluoride)

- Pyrohydrolysis of $\mathrm{UO}_{2} \mathrm{~F}_{2}$ at $750{ }^{\circ} \mathrm{C}$ in a rotary kiln to uranium sesquioxide $\mathrm{U}_{3} \mathrm{O}_{8}$

Main reactions involved:

(1) Hydrolysis

$$
\mathrm{UF}_{6}+2 \mathrm{H}_{2} \mathrm{O} \rightarrow \mathrm{UO}_{2} \mathrm{~F}_{2}+4 \mathrm{HF}
$$

(2) Pyrohydrolysis

$$
\underset{1 / 6 \mathrm{O}_{2}}{\mathrm{UO}_{2} \mathrm{~F}_{2}}+\mathrm{H}_{2} \mathrm{O} \rightarrow 1 / 3 \mathrm{U}_{3} \mathrm{O}_{8}+2 \mathrm{HF}+
$$

Received: July 18, 2005

[1] C.R. Edwards, A.J. Oliver, 'Uranium Processing: A Review of Current Methods and Technology', J. Metallurgy, September 2000, pp. 12-20.

[2] L. Rigo, R. Faron, 'Raffinage et conversion des concentrés d'uranium', in Les Techniques de l'Ingénieur. - Paris, Traité Mécanique et Chaleur B 3 590, 1996.

[3] S. Jaccaud, F. Nicolas, 'Fluor', in Les Techniques de l'Ingénieur - Paris, Génie et Procédés chimiques J 6 020, 1983.

[4] P.G. Alfredson, 'Review of Methods and Technology for the Production of Uranium Hexafluoride', AAEC Symposium on Uranium Processing - Lucas Heights 2021 July, 1972

[5] 'Uranium 2000, International Symposium on the Process Metallurgy of Uranium', Ed. E. Özberg, A.J. Oliver, 30th Annual Hydrometallurgical Meeting of the MSCIM - Saskatoon, Canada. Sept. 2000. 